\title{
La actividad cooperativa en Venezuela
}

\author{
Osta, Karelys* \\ Mendoza, Ermelinda** \\ Giraldo, Marisela***
}

\section{Resumen}

El cooperativismo ha sido presentado como un elemento estratégico del gobierno venezolano para incorporar sectores importantes de la población al desarrollo económico. Esta investigación tiene como objetivo explorar la actividad cooperativista en Venezuela, para lo cual se realizó un estudio, basado en fuentes secundarias. Se evidencian avances entre el modelo cooperativista prescriptivo, pero también diferencias al no haber propiciado cambios en el pensamiento de las personas incorporadas a este sector, en el cual deben imperar valores, normas y procedimientos disímiles a los del sector privado de la economía, especialmente en cuanto a la inexistencia de relaciones laborales de los asociados y los principios que las sustentan.

Palabras clave: Cooperativas, economía social, estrategia cooperativa, inclusión, Venezuela.

\section{Cooperative Activity in Venezuela}

\section{Abstract}

Cooperative activity has been presented as a strategic element by the Venezuelan government in order to incorporate important sectors of the population in economic development. The objective of this research is to explore cooperative activity in Venezuela. A study was undertaken

\section{Recibido: 04-12-03. Aceptado: 05-07-22}

Ingeniero Industrial. M.Sc. en Administración de Empresas. Profesora de la Escuela de Ingeniería Industrial. Universidad de Carabobo (UC). Autora del libro "Franquicia... ¿ tu oportunidad de negocio?". E-mail: kosta@uc.edu.ve

** Licenciada en Relaciones Industriales. M.Sc. en Administración del Trabajo y Relaciones Laborales. Profesora de la (UC). Acreditada en el Programa de Promoción al Investigador (PPI). E-mail: hemdoza1@uc.edu.ve

*** Ingeniero Industrial. M.Sc. en Administración de Empresas. Profesora de la Escuela de Ingeniería Industrial (UC). E-mail: mgiraldo@uc.edu.ve 
based on secondary sources. Advances are observed in the prescriptive cooperative model but also differences appear since changes have not occurred in the mentality of the people involved in this sector, in which values, norms and procedures different from those of the private sector of the economy should prevail, especially in relation to the inexistence of associated labor relations and their underlying principles.

Key words: Cooperatives, social economy, cooperative strategy, inclusion.

\section{Introducción}

Las expresiones de solidaridad y de cooperativismo que se pueden conseguir en Venezuela desde principios del siglo XX son variadas, van desde las conocidas experiencias de autoayuda desarrolladas por comunidades indígenas y campesinas, pasando por las cajas de ahorro, constituidas en diferentes ciudades del país como son los casos que se describen (Caracas, Valencia, La Guaira, Puerto Cabello, Maracaibo, Mérida en la década del 60 en adelante), hasta llegar al año 1999 cuando se incorpora en la Constitución Nacional el concepto de economía social, donde las cooperativas se erigen como pilar fundamental abriendo la posibilidad del desarrollo de actividades económica y culturales, adquiriendo así un impulso a nivel nacional.

Es justamente, tomando como referente lo formulado en la nueva Constitución que surge esta investigación, la cual tiene como objetivo analizar la actividad cooperativista en Venezuela, utilizando para ello entrevistas no estructuradas a cooperativistas, para luego emplear el método de análisis y síntesis, partiendo de los fundamentos de la economía social a través de un estudio de tipo documental.

\section{Características de la Economía social}

Al tratar el tema de la economía social es imprescindible detenerse en dos problemas fundamentales: la pobreza y la exclusión social, los cuales tienen que ver con aspectos más profundos al simple nivel de ingresos, según el Programa "Estrategias y Técnicas contra la Exclusión Social y la Pobreza de la OIT" (OIT, 1998): “... el análisis de la exclusión social se interesa a las causas de la pobreza, a la especificidad de las necesidades esenciales en las diferentes sociedades, al acceso a los servicios y oportunidades que permiten satisfacer dichas necesidades, a los derechos civiles y políticos de las personas y, en particular, a los derechos fundamentales de los trabajadores según les ha estipulado la OIT".

En este contexto, la economía social se ha convertido en un medio a partir del cual se concreta la lucha contra la exclusión social, canalizando y convocando la participación activa de las personas excluidas, creando instancias de diálogo y concertación que posibiliten dicha participación, procurando la organización de los individuos con el fin de llevar a cabo diversas actividades destinadas a mejorar sus ingresos, acceder a los servicios socia- 
les, hacer valer sus puntos de vista, defender sus intereses y negociar sus relaciones frente a terceros y al Estado, potenciando así los canales de acceso al desarrollo de sus propias familias y localidades, logrando su inclusión en el sistema productivo de los países.

Sin embargo, el concepto de economía social es un concepto en desarrollo, razón por la cual, no se cuenta con una definición concreta; las distintas acepciones dependen de cada país y tienden a coincidir en algunos elementos básicos. Según la OIT (1998), muchos países, para englobar las actividades relacionadas con este ámbito, las designan con el nombre de sector de economía social (Costa Rica, Perú), economía solidaria (Colombia) o sector social de la economía (México).

Particularmente en Venezuela, esta figura toma los nombres de economía social y participativa y economía asociativa, en la Constitución Nacional (ANC, 1999) y en la Ley Especial de Asociaciones Cooperativas (LEAC) (Asamblea Nacional, 2001), y los de economía popular productiva, economía solidaria, entre otras, evidenciadas en los distintos planes, programas y documentos de los organismos gubernamentales y empresas estatales como Petróleos de Venezuela Sociedad Anónima (PDVSA).

El sector de la economía social es considerado por el actual gobierno de Venezuela como una vía para superar la exclusión, es la combinación de la economía privada con la economía social. Es así como al efecto, la Carta Magna, en el título "De los Derechos Económicos", protege la libre empresa, la iniciativa privada y la propiedad individual. La libertad de empresa se garantiza en el artículo $112 \mathrm{y}$, en el 113 se protege la libre competencia, con la que, según el artículo 299, se erigen las bases para el mejoramiento de la economía nacional a fin de generar fuentes de trabajo y elevar el nivel de vida de la población.

En el artículo 118 de la Constitución, establece el reconocimiento legal a una Economía Social y Participativa que vendría a constituir parte de lo que se ha denominado tercer sector de la economía, que se ubica entre el público y privado. En palabras de Perdomo (2003), ésta debería tener la orientación de una economía "de los usuarios, de los consumidores y de los trabajadores que actuando bajo el sentido comunitario, democrático interno y profundo, otorgue al pueblo una fuerza económica y una fuerza de vivencia de una vida distinta que fortalezca las relaciones humanas." En este sentido, resulta interesante reflexionar acerca del trabajo, sus actores y las relaciones entre ellos.

La cuestión central viene a ser ¿cómo y quién representa las nuevas figuras del trabajo en la economía social?, o de modo más preciso ¿son sujeto de representación? La respuesta es paradójica, en tanto expresión concreta y subordinada de la organización del trabajo en este segmento de la economía donde, la organización del trabajo se abre a la implicación de los trabajadores y de los clientes y a un marco regulatorio diferente al de la Ley Orgánica del Trabajo (Comeau et al, 2002).

La Confederación Empresarial Española de Economía Social (CEPES), $(\mathrm{S} / \mathrm{F})$, define a la economía social "como toda actuación económica que actúa en el mercado o en la sociedad, que indepen- 
dientemente de su fórmula jurídica, comparte los principios de: organización democrática, la persona antes que el capital, propiedad horizontal, reparto de beneficios/resultados con criterio colectivo, especialmente solidaria con el entorno y provocadora de cohesión social".

En 1987, Ravina citado por Suárez (2003), como presidente del Instituto de Economía Social para la época, afirmaba: "la economía social es el sector de la economía privada (por oposición a la economía estatal) dirigido al interés general y que no persigue fines de lucro. Se caracteriza por las relaciones entre sus miembros y entre éstos y los órganos sociales, que se determinan conforme con las reglas de la democracia y de la no discriminación (...) Creemos que en una democracia pluralista, en una democracia social, el sector de la economía que propiciamos integra participativamente al hombre en la gestión económica y marca un rumbo definido en el camino de su emancipación y dignificación. Su influencia es decisiva para corregir la desviación de los otros sectores".

Así mismo, en 1984 Vainstok, maestro de la cooperación a nivel mundial, referido por Suárez (2003), planteó que: "El concepto de "economía social" corresponde a las estructuras económicas que nacen de la clase obrera y artesanal (productores rurales y urbanos), como instrumento de defensa solidaria en el contexto del sistema económico capitalista vigente. La noción de servicio social organizado por la acción de asistencia mutua, con el único objeto del bien común, genera un universo económico diferenciado del contexto de la economía de mercado que opera en función de la ganancia óptima".

Según la tesis aprobada por la Confederación Empresarial Española de Economía Social (CEPES) en Asamblea Extraordinaria a principios del año 2001, el concepto de economía social comprende cualquier forma empresarial que integre a todas las novedades organizativas y sus correspondientes figuras jurídicas, surgidas como respuesta a las diversas necesidades que plantea la cohesión social. En este sentido, son parte de la economía social las cooperativas, sociedades laborales, mutualidades de previsión social, centros especiales de empleo, fundaciones y asociaciones.

Independientemente de los nombres que recibe en los distintos países, la economía social presenta características esenciales inherentes a su propia condición, las cuales se puntualizan a continuación:

- Promueve el desarrollo integral de la persona como un fin en sí mismo, convirtiendo el capital en un instrumento.

- Persigue objetivos económicos, sociales y de interés general y colectivo, por encima de los individuales.

- Contribuye a la incorporación al mercado de trabajo de colectivos víctimas de la exclusión social: jóvenes en búsqueda de su primer empleo, mujeres, desempleados de larga duración, personas con discapacidad, minorías étnicas e inmigrantes.

- Promueve la participación activa y voluntaria de las personas en la autogestión y búsqueda de las soluciones a problemas comunes. 
- Contribuye de manera directa al logro de mayores niveles de cohesión y bienestar social de la comunidad con una visión integral.

\section{Cooperativismo: Caracterización}

El cooperativismo, como un segmento de la economía social, de acuerdo a lo expresado por Richer (1999), surge como una simbiosis entre las organizaciones parlamentarias democráticas, las organizaciones capitalistas y la organización sindical, de las cuales tomó sus elementos esenciales, a saber: los valores fundamentales de libertad e igualdad basando su funcionamiento en las reglas de las instituciones democráticas, la responsabilidad limitada y la división de la propiedad en partes $y$, finalmente, la equidad y la solidaridad. Es así como el cooperativismo es un movimiento socioeconómico de carácter mundial, constituido por asociaciones económicas cooperativistas en las que todos los integrantes son beneficiarios de su actividad según el trabajo que aportan (SUNACOOP, 2003).

Según García-Gutiérrez citado por Vargas (2001), el cooperativismo trata de un sistema organizado alrededor de unas relaciones sociales que buscan situar a la persona por encima del capital. El grado de compromiso de los socios en la empresa se pone de manifiesto especialmente en la lealtad hacia la organización, por ejemplo, al no desviar la producción hacia otro tipo de empresa; y en el grado de participación de los socios en los órganos sociales de la sociedad cooperativa. También se plasma el compromiso de los socios en la política de autofinanciación, pues generalmente cuando se ha de acometer algún proyecto empresarial en la organización o se necesitan fondos, éstos son aportados por los socios en función de su contribución a la actividad cooperativa.

La sociedad cooperativa, como señala Morales Gutiérrez citado por Vargas (2001), es la empresa humana, la empresa personalista por excelencia, un modelo empresarial configurado en torno a un valor básico: la soberanía de la persona sobre el resto de los factores productivos. Parodiando el afortunado y clásico eslogan de las cajas de ahorro, "la cara humana del dinero", Vargas (2001) plantea que podría hablarse de las cooperativas como "la cara más humana del capitalismo".

Estas organizaciones procuran conseguir el desarrollo sostenible de sus comunidades, a través de políticas formuladas y aceptadas por sus miembros. Igualmente proporcionan educación, capacitación, adiestramiento, formación e información a todos sus integrantes. También aplican enfoques, técnicas y herramientas gerenciales, crean y desarrollan sus propias culturas empresariales, además, son el resultado de iniciativas de emprendedores para satisfacer sus propias necesidades, definiendo objetivos y estrategias para mantenerse en el tiempo.

Según García-Gutiérrez (1991), las fortalezas de las empresas cooperativas son: 1. La participación del socio en los tres tipos de flujos que tienen lugar en una empresa: flujos de información-decisión, participando democráticamente (un socio $=$ un voto) en los órganos sociales (participación en la gestión), flujos reales, interviene como proveedor y/o como consumidor y flujos financieros, apor- 
tando capital y participando en los excedentes; se encuentra ligada a la participación del socio en el proceso de producción y/o distribución (flujos reales), es decir, en proporción a la actividad cooperativizada. 2. La doble (o triple) condición de socio/proveedor y/o socio/consumidor, constituyéndose en elemento favorable para que estas empresas estén orientadas hacia la calidad y 3 . La condición democrática de sus líderes: se trata de quién es capaz de crear el ambiente propicio para que cada integrante de la organización soporte su parte de la carga. Por su cualidad de servidores, está en situación de asumir, mejor que cualquier otra empresa, este nuevo papel del liderazgo.

Es importante que el cooperativista conozca los lineamientos mediante los cuales las empresas asociativas pondrán en práctica sus valores: ayuda mutua, responsabilidad, democracia participativa, igualdad, equidad y solidaridad, como también, sus principios: asociación abierta y voluntaria, gestión democrática de los asociados, participación económica igualitaria de los asociados, autonomía e independencia, educación, entrenamiento e información, cooperación entre cooperativas y el compromiso con la comunidad. Filosofía que, en adición al número de accionistas, ejercicio del poder, capital, movilidad de las acciones y distribución de ganancias, lo diferencian de las empresas de tipo mercantilista (SUNACOOP, 2003).

La Conferencia Internacional del Trabajo 2002, de acuerdo a lo establecido en la Recomendación № 127 (OIT, 1966) y en la № 193 sobre la Promoción de las Cooperativas (OIT, 2002), adopta formalmente la creación de cooperativas como medio para el progreso económico y social de los países en vías de desarrollo y la lucha contra la pobreza, contribuyendo con los postulados de la Agenda del Trabajo Decente ${ }^{1}$, jugando un papel crucial en el desarrollo económico, social y cultural, así como de la promoción humana. Según la OIT (2002), las cooperativas deberían establecerse con el fin de:

- Mejorar la situación económica, social y cultural de las personas con recursos y posibilidades limitados, así como fomentar su espíritu de iniciativa y la creación de empleos.

- Conservar los empleos ya existentes, al permitir a los productores unir sus fuerzas para salvar sus empresas.

- Contribuir a la economía con un elemento más amplio de control democrático de la actividad económica y de distribución equitativa de excedentes.

- Aumentar la renta nacional y las posibilidades de empleo mediante una explotación más completa de los recursos, realizada, por ejemplo, gracias a la aplicación de sistemas de reforma agraria y colonización que tien-

1 "El trabajo decente... implica oportunidades de obtener un trabajo productivo con una remuneración justa, seguridad en el lugar de trabajo y protección social para las familias, mejores perspectivas para el desarrollo personal y la integración social, libertad para que los individuos manifiesten sus preocupaciones, se organicen y participen en la toma de aquellas decisiones que afectan a sus vidas, así como la igualdad de oportunidades y de trato para mujeres y hombres" (http://www.ilo.org/public/spanish/decent.htm) 
dan a convertir en productivas nuevas regiones.

- Permitir a los ciudadanos más pobres acceder a servicios sociales básicos, como servicios de salud, cuidado infantil y atención preescolar, cuidado de ancianos o servicios comunitarios, producto de su propia organización.

- Servir de puente para que trabajadores de la economía informal pasen al sector formal mediante su participación en procesos de toma de decisiones y de negociación de condiciones y precios con sus clientes. Se destaca la naturaleza democrática de las cooperativas, incluyendo el principio de libertad de participación, sin discriminación alguna.

Finalmente es importante señalar que el campo del cooperativismo implica un cambio radical en la estructura mental de los asociados, ya que requiere pasar de los paradigmas individualistas de la cultura occidental a la visión del bienestar colectivo, lo cual amerita grandes esfuerzos en materia de formación en el campo del cooperativismo que permitan divulgar su esencia con el fin de evitar la aparición de las deformaciones de sus principios y valores fundamentales, donde los distintos actores involucrados (Estado, cooperativas y asociados) ejerzan en su justa medida cada uno de los roles correspondientes según sus respectivos ámbitos de acción.

En este sentido, cuando el Estado deja de ser promotor y protector de la actividad cooperativa, cuando las cooperativas dejan de ser instrumentos para el desarrollo y mejora de la calidad de vida de sus asociados y de la localidad donde se desenvuelven sus actividades, cuando los asociados dejan de concebir su responsabilidad en la gestión y su trabajo como el principal aporte en beneficio del progreso de todos; es entonces el momento cuando este medio concebido para alcanzar la inclusión de los excluidos de la sociedad, se convierte en la práctica en: a) Empresas capitalistas cuyos beneficios sólo son percibidos por pocos. b) Medios para la explotación de los trabajadores no asociados. c) Un Estado financista y promotor de subsidios de actividades no productivas e ineficientes. d) Un medio para excluir a los asalariados de los beneficios de la Ley Orgánica del Trabajo, contrataciones colectivas, sistema de seguridad social y posibilidad de sindicalización. e) Impulsores de un nuevo tipo de exclusión por razones distintas a las que le dieron origen, por ejemplo, de naturaleza política e ideológica.

\section{El cooperativismo en Venezuela}

Variadas son las expresiones de solidaridad y de cooperativismo que pueden encontrarse en Venezuela, desde las experiencias de autoayuda desarrolladas por comunidades indígenas y campesinas, hasta las de cajas de ahorro constituidas en Caracas, Valencia, La Guaira, Puerto Cabello, Maracaibo, y Mérida. Por ello, hablar de la historia del cooperativismo implica considerar tres períodos: el primero se inicia con la primera cooperativa hasta comienzos de la democracia representativa en 1958, el segundo desde el establecimiento del proceso democrático, hasta el surgimiento de las Centrales Cooperativas Regionales (CCR's) y la Central Cooperativa Nacional de Vene- 
zuela (CECONAVE), y el tercero se extiende hasta la actualidad (Bastidas, 2003); siendo este último período en el cual se centra este análisis.

\subsection{Marco legal vigente}

En Venezuela, con la Constitución Nacional de 1999 se afianza formalmente el concepto de economía social y las cooperativas se erigen como su pilar fundamental, evidencia del rol protagónico y participativo de los ciudadanos en la administración, regulación y toma de decisiones. En sus diferentes artículos (Arts. $3,70,117,118,184,299$ y 308), se deja plasmado su papel en el ejercicio de la soberanía del país en el orden social y económico, abriendo la posibilidad del desarrollo de cualquier tipo de actividad económica y reconociendo a través de la Ley las especificidades de dichas organizaciones, en especial las relativas al acto cooperativo, al trabajo asociado y a su carácter generador de beneficios colectivos, quedando el Estado comprometido a su protección y promoción con el fin de fortalecer el desarrollo económico, sustentado en la iniciativa popular, así como a garantizar la capacitación, la asistencia técnica y el financiamiento oportuno.

En el marco de la nueva Constitución, surge la Ley Especial de Asociaciones Cooperativas (LEAC) (Asamblea Na- cional, 2001), con el fin de normar el sector y proveer de un marco regulatorio específico para orientar los planteamientos presentes en la nueva Constitución. Ésta establece las legalizaciones de las cooperativas, facilitando su constitución al permitir el trámite correspondiente ante el registro de la localidad, transfiriendo al estatuto sus formas, modalidades y mecanismos de organización y de los entes que ellas constituyen en su proceso de integración (cooperativas de segundo grado $)^{2}$, dando así una mayor flexibilidad y capacidad de evaluación y adaptación de sus estructuras a los procesos cambiantes del entorno.

Así mismo, promueve la organización flexible de las cooperativas, establece normas para el desarrollo del trabajo asociado, impulsa los procesos de integración cooperativa con sistemas de educación, información, comunicación, conciliación y arbitraje, fortalece y especifica la función de contraloría de la Superintendencia Nacional de Cooperativas (SUNACOOP), establece las modalidades de promoción y protección del Estado, las cuales se ven expresadas en la exención de todo impuesto, tasa o contribución de aquellas debidamente certificadas, con el objeto de estimular el desarrollo de este sector de la economía.

A través de los planteamientos de la LEAC se incentiva la participación de

Atendiendo a la naturaleza de los socios, las cooperativas pueden clasificarse en : 1.Cooperativas de primer grado las cuales agrupan como mínimo a cinco socios que se unen por intereses socio-económicos comunes y 2. cooperativas de segundo grado y tercer grado; integran cooperativas de la misma o distinta clase, teniendo como objetivos promover, coordinar y desarrollar fines económicos comunes a los socios, así como reformar la actividad económica de las mismas. Es lo que se podría llamar cooperativas de cooperativas, conformando las federaciones y confederaciones. 
los trabajadores y la comunidad en la gestión de las empresas públicas y privadas, estimulando la difusión de las experiencias nacionales e internacionales de los procesos organizativos exitosos de las cooperativas, estableciendo expresamente la igualdad de condiciones para su participación en las compras y concesiones del Estado, así como las distintas modalidades de atención financiera del Estado y demás entes públicos y privados dirigidos a fortalecerlas de manera particular, además de los propios sistemas cooperativos de financiamiento.

En cuanto al trabajo como elemento fundamental de la actividad cooperativa, la LEAC define las características del trabajo asociado (Arts. 30, 31 y 32), las regulaciones aplicables (Art. 34), el trabajo excepcional de los no asociados (Art. 36), las modalidades de trabajo asociado en los organismos de integración y entes similares, los mecanismos propios de protección social y la vinculación con los sistemas de seguridad social.

Estos aspectos son de importancia fundamental al analizar las relaciones laborales y la constitución de los distintos actores en estas organizaciones de carácter colectivo, ya que, en el ámbito cooperativista éstas no existen entre los asociados y la organización, son copropietarios, cogestores y responsables de la coadministración y toma de decisiones acerca de los cursos de acción a seguir. Tal concepción desdibuja la figura del salario como remuneración al factor de producción trabajo, para transformarse en una responsabilidad y una contribución al acto cooperativo.

Al enfocarlo desde el punto de vista de los actores que se conforman alrede- dor de esta forma, nada nueva, de la organización del trabajo, la cooperativa misma se erige como empresa y, a la vez, ente encargado de velar por la justa distribución de los beneficios generados a partir de la actividad cooperativista, basada en sus valores y principios, al repartir los excedentes equitativamente entre los asociados.

Estas circunstancias hacen evidente en las cooperativas un doble rol frente al hecho del trabajo, como promotor, generador y garante del empleo en el largo plazo, para lo cual es necesaria su permanencia en el tiempo a través del éxito en la autogestión (rol empresarial) y como garante de la seguridad social de los asociados, mejora de su calidad de vida y beneficios a la comunidad donde se desenvuelven y, en cuyo progreso, se fundamenta el desarrollo sustentable de su actividad (rol social). Se podría decir que, simultáneamente, asume las responsabilidades de empresarios y sindicatos existentes en las empresas privadas.

\subsection{El cooperativismo reciente en el país}

En Venezuela, hasta finales del siglo XX, el cooperativismo fue una actividad de carácter marginal; las crisis de los años setenta y los ochenta abonaron el terreno para su incorporación en la Constitución de 1999, como actividad prioritaria protegida por el Estado. Al efecto, para reducir el desempleo de $16 \%$ a menos de $10 \%$ (Celis, 2004), el gobierno venezolano decidió crear pequeñas empresas, reactivar parques industriales, estimular la contratación de empresas nacionales en los proyectos de compras del Estado y 
fomentar la conformación de asociaciones de cooperativas. Como parte del plan estratégico de la economía social para la transformación del sistema económico y social contaban con el Banco de la Mujer, Bandes, Fondemi y el Banco del Pueblo, entidades con énfasis en las microfinanzas (MPC, 2003).

Según este autor, a fin de generar un crecimiento del Producto Interno Bruto de entre 5\% y $7 \%$, la SUNACOOP adaptó su estructura para colaborar con los programas emanados del plan económico 2002-2007. En el área turística el organismo pretendía recuperar la infraestructura mediante la conformación de empresas cooperativas, mayoritariamente con habitantes de las zonas de desarrollo endógeno pautadas por el Ministerio de la Planificación y Desarrollo; para lo cual, la población debe asociarse para impulsar cadenas productivas, tanto agrícolas -en todos sus rubros- como industriales, incluyendo aluminio, plástico, metalmecánico, textil-confección y turismo, a fin de crear nuevas empresas y garantizar el autosostenimiento de las nuevas zonas estratégicas en las regiones más deprimidas.

Según Celis (2004), en el año 2004 existían en el país 18.185 empresas cooperativas distribuidas en los rubros siguientes: $48 \%$ servicio y suministro de bienes (8.641), 31\% área agropecuaria (5.646), $13 \%$ sector transporte (2.311), $4 \%$ actividades de consumo (658), 4\% servicios sociales (720) y $1 \%$ ahorro y crédito (209), previéndose un crecimiento de $8 \%$ para llegar a 19.640 cooperativas en este mismo año; siendo consideradas claves en este momento las poblaciones de Cabruta, San Fernando y Carabobo para la creación de un eje agroindustrial basado en la cadena textil-confección, con el fin de lograr el aprovechamiento del potencial de siembra de algodón que tiene el país en Las Vegas del Orinoco.

Otro segmento considerado prioritario por la SUNACOOP es el sector petrolero, donde se detectó la necesidad de crear asociaciones cooperativas para brindar apoyo al sector. Al efecto se intenta organizar la población que habita en la zona de la Refinería El Palito, en el estado Carabobo, y las demás instalaciones petroleras hasta llegar al estado Barinas con la finalidad de garantizar la seguridad, mantenimiento y desarrollo de esos centros claves para el país, siendo la industria petrolera la responsable de impartir la capacitación a los cooperativistas y financiarlos mediante un fondo especial administrado por la Corporación Venezolana del Petróleo (CVP). Celis (2004) afirma que:"Se trata de crear cooperativas integrales de mantenimiento con la industria petrolera. Es decir que no sólo garanticen el mantenimiento de las áreas adyacentes a las plantas petroleras y a los oleoductos, sino que también sirvan como una gran red de servicio de vigilancia. Estas asociaciones, a su vez, se constituirán en granjas productivas mediante las cuales se proveerá de recursos alimenticios a los poblados más pobres."

Con este propósito, a finales del año 2003, el gobierno nacional organizó rondas de negocios en diferentes regiones del país y el Primer Encuentro de Automatización, Informática y Telecomunicaciones de (PDVSA), orientado a estimular el desarrollo del sector tecnológico nacional, especialmente hacia las cooperativas, pequeñas y medianas empresas (Díaz, 2003). Sin embargo, existen temo- 
res respecto a la producción, mediante cooperativas, en particular en el área de productos químicos utilizados en el petróleo y el mantenimiento en dicho sector (Bocco, 2003), es el caso de los proyectos para incluir en los trabajos de deforestación y mantenimiento de las tuberías y las veinticuatro cooperativas inscritas en PDVSA GAS, del estado Guárico (Chopite, 2004).

Es oportuno destacar que, en la actualidad, 220 cooperativas prestan servicios a PDVSA y dentro de la reestructuración se planea la reformulación de los sistemas de distribución interna del combustible (formación de cooperativas de camiones cisternas), y la provisión de bienes y servicios de empresarios nacionales a PDVSA (Aharonian, 2003). De igual forma, para el año 2004, se tenía como meta desarrollar un programa similar, con las empresas hidroeléctricas -CVG-Electricidad del Caroní, Cadafe y sus filialesy las hídricas, para proporcionar a través de las cooperativas servicios de mantenimiento a las respectivas instalaciones (Celis, 2004).

En el sector industrial, el Ejecutivo Nacional creó, mediante decreto del año 2003, la empresa Venezolana Industrial Sociedad Anónima (Veninsa), una empresa estatal cuya finalidad es apoyar financiera y técnicamente a otras industrias y cooperativas de desarrollo. Con un capital promedio de 30 millardos de bolívares busca promover las alianzas estratégicas entre empleados y empresarios, para reactivar 500 fábricas que quebraron por la crisis bancaria de los noventa y que están en manos del Fondo de Garantía de Depósito y Protección Bancaria (FOGA$D E)$. "El proyecto consiste en organizar a los trabajadores en cooperativas con el objeto de reactivar las empresas cerradas y que no cancelaron los pasivos laborales. En tal sentido, Veninsa, empresa del Estado que se espera su despegue para este año, capitalizará, inyectará recursos y tendrá acciones de otras empresas en el área agroalimentaria y de otros servicios. Será una empresa con el fin de expresar la propiedad estatal sobre la nueva economía social" (Celis, 2004).

Parafraseando a Bastidas (2003), en la Venezuela actual con sus crisis, peso del desempleo, la pobreza y la fragilidad de su sistema económico, entre otros, obligaron a pensar en el cooperativismo como vía para enfrentar dichos problemas. En línea con esta idea, se pueden identificar fortalezas que dan cuenta de opciones positivas para enfrentar la crisis e impulsar el cooperativismo adecuadamente. No obstante, formando parte del tercer período del cooperativismo en el país en el gobierno del Presidente Hugo Chávez el cooperativismo es la "punta de lanza de su gestión". En consecuencia, el cooperativismo y la Economía Social que aparecen en el texto en la Constitución Nacional de 1999, unido al proceso de reforma de la Ley General de Asociaciones Cooperativas de 1975 hasta la promulgación de la de 2001; y otras acciones gubernamentales, condujeron al nuevo cooperativismo y a la creación del Ministerio de Desarrollo de la Economía Social. Según Bastidas (2003): “... el crecimiento desmesurado y desordenado del nuevo cooperativismo como consecuencia, en parte, del facilismo extremo y las ligerezas en el proceso de constitución de cooperativas.... fomentar la creencia generalizada por parte 
del Presidente de que el gobierno financiará cualquier cooperativa que se constituya, produce terribles daños a los aspectos económico organizacionales de las cooperativas. La no exigencia de capacitación previa a la constitución o como requisito de asociación, resta importancia a los principios, valores y prácticas democráticas, igualan las cooperativas con cualquier empresa de capital".

Por otra parte, la ausencia de estudios de viabilidad económica de la cooperativa convierte este requisito en simple relleno del modelo de estatutos elaborado por SUNACOOP, situación que atenta contra la flexibilidad exigida por la Ley, castrando las reflexiones acerca de su objeto, sus recursos, y su estructura; por lo que estas ligerezas pueden dar lugar a que este proceso de creación de cooperativas pueden conducir al desarrollo de organizaciones cooperativas, vacíos de cooperativismo desde el punto de vista ético (Bastidas, 2003).

Siguiendo con el autor en referencia, entre las características de estas nuevas cooperativas se pueden mencionar las siguientes: 1. La mayoría se constituyen con visión de inmediatez y sin obedecer a una política seria de promoción y desarrollo cooperativo. 2. Numerosas nuevas cooperativas se alejan demasiado de los preceptos de valores, principios y organización socioeconómica que las cooperativas deben poseer. 3 . Se observa ausencia absoluta de: valores y principios; proyectos y planes organizacionales, visión compartida, identidad cooperativa, consistencia humana en lo asociativo y la fortaleza económica y de gestión empresarial, para garantizar sus- tentabilidad en el tiempo, mecanismos de integración e intercooperación, salvo aquellas con orientación política definida. 4. Un alto porcentaje de las constituidas lo hacen para lograr apoyo económico. 5. No existe información acerca de la capacitación suministrada a los nuevos cooperativistas; algo debe estar haciéndose pues las magnitudes y exigencias del sector son grandes. Según Bastidas (2003) "Es deseo del autor que todas las experiencias emprendidas sean exitosas pero el crecimiento desordenado, sin valores y otros elementos básicos de un cooperativismo convencido de su importancia para un país distinto, hacen que no sea así. Sin dudar de las nobles intenciones de numerosos nuevos cooperativistas, de su empeño, búsqueda de éxito con bases en valores, principios, y atención a los manejos económicos, la simple inercia en estas nuevas cooperativas por la ausencia de unos financiamientos y apoyos en lo cuales creyeron, ya torna sombrío el futuro de numerosas de ellas. Muchas ya fracasaron y otras pudieran hacerlo en poco tiempo" Bastidas (2003).

\subsection{Retos del movimiento cooperativo y Rol del Estado}

En el campo del cooperativismo, sobretodo en Venezuela, se presentan retos, particularmente en dos aspectos fundamentales:

- La necesidad de garantizar a sus asociados la seguridad social ante cualquier contingencia, lo cual está vinculado a la calidad de vida de los mismos y los requerimientos de recursos que acarrea, especialmente ante la carencia de un sistema de seguridad 
social dependiente del Estado, capaz de dar respuesta ante situaciones relacionadas con la salud, muerte, accidentes, etc.

- El logro de la promulgación de una Ley Orgánica de Cooperativas, la cual le otorgaría la posibilidad de dirimir sus controversias en tribunales especiales en materia cooperativa, que contemple las particularidades de la naturaleza de sus actividades y fines colectivos.

De esta forma el sistema cooperativista contaría con las bases para su desarrollo armónico, ya que, la distorsión en el rol de los actores del referido movimiento, Estado, cooperativas y asociados, puede llevar a la pérdida de la razón de ser de tal forma de organización del trabajo, y, lejos de lograr su función de incluir a los excluidos, da origen a una exclusión debida a razones distintas a las de la pobreza, sino a una exclusión basada en la propiedad del capital o en ideologías políticas, debiéndose tener presente que, el rol al cual está llamado el Estado es: 1. Promover la competencia en igualdad de condiciones de las empresas de la economía social en el mercado. 2. Proveer de un sistema de seguridad social a la población. 3. Favorecer las empresas de la economía social a través de un tratamiento fiscal preferencial como incentivo económico. 4. Estimular la incorporación de las empresas de economía social a la formación continua de sus asociados y de la comunidad en general. 5. Incorporación de las cooperativas y sociedades laborales a los planes y programas de fomento del empleo. 6. Establecer los mecanismos de financiamiento de proyectos de inversión, implantación de las nuevas tecnologías de la información y las comunicaciones, los cuales prevean condiciones de pago favorables (plazos, tasas de interés, entre otras). 7. Promover el desarrollo de la integración empresarial en todos sus ámbitos, público y privado. 8. Facilitar la profesionalización de la gestión y la formación de los socios y dirigentes. 9. Proveer de un marco normativo donde se estimule y promueva las asociaciones dentro de la sociedad civil en la búsqueda de su propio bienestar. 10. Procurar una mejor coordinación de las políticas gubernamentales, en sus distintos niveles, a fin de lograr la mayor coherencia en el trato de las empresas de la economía social.

\section{Conclusiones}

La economía social intenta dar respuesta a una situación de exclusión social en la cual se encuentra inmersa gran parte de la población mundial, realidad a la cual no escapan América Latina ni Venezuela, ante la incapacidad del Estado y del sector privado de lograr brindar un desarrollo económico con una distribución adecuada de la riqueza que le permita a la sociedad alcanzar un mínimo de calidad de vida y bienestar, garantizando a la población el acceso a aspectos fundamentales como la salud, seguridad social, educación y trabajo.

La poca información existente sobre el movimiento cooperativo en Venezuela en la época previa al surgimiento de la democracia participativa, da cuenta de la escasa relevancia del cooperativismo previo a 1959. En los años posteriores se conoce el auge del movimiento, cuando en los años 70's se da constitución de las CCR's y CECONAVE; pero es con la en- 
trada en vigencia de la Constitución $\mathrm{Na}$ cional de 1999 cuando se establece el reconocimiento legal de la Economía Social y Participativa que que viene a formar parte del tercer sector de la economía venezolana, además del público y privado, donde las cooperativas se constituyen en pilar fundamental.

El trabajo asociado como elemento fundamental de la actividad cooperativa, amerita un proceso de aprendizaje y cambio, así como la organización de los mecanismos de protección social y la vinculación con los sistemas de seguridad social que le son propios, como un reflejo de la simbiosis entre su rol empresarial y sindical.

En el caso específico de las organizaciones venezolanas, se evidencia una marcada distancia entre el modelo teórico del movimiento cooperativista y la realidad actual, por cuanto su utilización está orientada por elementos de orden político, con el agravante de que no se han producido cambios en la forma de pensar y actuar de los nuevos grupos de personas incorporadas a este segmento de la economía, en el cual deben imperar normas, procedimientos y valores distintos a los existentes en la economía de mercado, es decir, congruentes con los principios de libertad, igualdad, responsabilidad limitada, división de la propiedad en partes, equidad y solidaridad.

Por otra parte, el rol del Estado debe definirse no sólo como ente promotor de la actividad cooperativista a través de su contratación preferencial por parte de sus distintos entes o del otorgamiento de financiamiento. También es necesaria la competencia en igualdad de condiciones entre las empresas de la economía social, un sistema de seguridad social de calidad, su incorporación a los planes y programas de fomento del empleo productivo, implantación de las nuevas tecnologías de información y comunicación, la integración empresarial en todos sus ámbitos (público y privado), la profesionalización de la gestión, la formación de los socios, dirigentes y de la comunidad en general.

En caso contrario, no pasará de ser sólo un mecanismo al servicio de unos pocos, donde las posibilidades de subsistencia serán limitadas, ante el fracaso económico que pudieran representar las "nuevas experiencias cooperativistas" dada la falta de formación y capacidad para dar respuesta adecuada a las necesidades técnicas de las empresas y entes contratantes, así como a las expectativas de los propios asociados.

Esta situación resalta la necesidad de hacer emerger un nuevo paradigma, donde la búsqueda de mayor productividad sea justamente pagada por los actores involucrados y donde se ponga de relieve la primacía del ser humano sobre el proceso de producción, para lo cual resulta imprescindible retomar la concepción del hombre como sujeto del trabajo y superar la antinomia entre trabajo y capital, al estructurarse el nuevo paradigma sobre la sustancial y efectiva prioridad del trabajo, la subjetividad del trabajo humano y de su participación eficiente en todo el proceso de producción, aspectos congruentes con los principios del movimiento cooperativo pero que amerita llevar adelante un proceso de aprendizaje que abarque tanto las estrategias de acción, como los valores dominantes. 


\section{Referencias Bibliográficas}

Aharonian, Aram (2003), Venezuela: La Renacionalización de PDVSA

ALAI, América Latina en Movimiento 06/01/03 [Disponible en: www.alainet.org/active. Consultado el 23 de junio de 2004].

Asamblea Nacional (2001), Ley Especial de Asociaciones Cooperativas. Decreto № 1440 . Gaceta oficial № 37.285 de fecha 18 de septiembre de 2001.

Asamblea Nacional Constituyente (1999), Constitución de la República de Venezuela. Gaceta Oficial 5.453 del 24 de marzo de 2000.

Bastidas, Oscar (2003), El Cooperativismo en Venezuela. Red Universitaria de Las Américas en Estudios Cooperativos y Sociativismo (UNIRCOOP). [Disponible en: http://www.unircoop.org/documents/coop/Venezuela.

pdf. Consultado el 17 de julio de 2004].

Bocco, Miguel (2003), Recuperan a Pdvsa Sacrificando a Trabajadores y Tecnología. Semanario La Razón No. 438 (Venezuela) - 01/06/03 [Disponible en: www.soberania.info. Consultado el 03 de julio de 2004].

Celis, Augusto (2004), Movimiento Cooperativista Venezolano: Reactivación y Generación de Empleo. En Red Voltaire 23 de abril de 2004 [Disponible en: http://www.redvoltaire.net/article802.html. Consultado el 17 de julio de 2004]

Comeau, Yvan; Boucher, Jacques; Malo, Marie-Claire y Vaillancourt, Yves (2002), Las Configuraciones de las Iniciativas de la Economía Social y Solidaria. CAYAPA Revista Venezolana de Economía Social, Año 2, № 3, Junio 2002, Venezuela, Centro de Investigación para el Desarrollo Integral Sustentable (CIDIS), Universidad de
Los Andes [Disponible en: http://www.saber.ula.ve. Consultado el 14 de julio de 2004].

Confederación Empresarial Española de Economía Social (CEPES) (S/F), Economía Social. [Publicación en línea]. [Disponible en: http://www.cepes.es/ sumseccion3.cfm. Consultado el 17 de julio de 2004].

Chopite, Luis (2004), La Nueva PDVSA GAS Fortaleciendo la Participación del Pueblo Organizado. [Disponible en: http://www.pdvsa.com/noticias/2004/enero Consultado el 13 de julio de 2004].

Díaz, David (2003), PDVSA Anunciará sus Necesidades de Bienes y Servicios Nacionales. Caracas, Venezuela, Octubre 07, 2003 [Disponible en: http://www.petrofinanzas.com. Consultado el 03 de Julio de 2004].

García-Gutiérrez, Carlos (1991), La Economía Social o la Economía de las Empresas de Participación (Las Sociedades Cooperativas y Laborales). En memoria de María Ángeles Gil Luezas, pp. 195-216. Madrid: Alfa Centauro.

Ministerio de Producción y Comercio (2003), Pymes y Cooperativas Ofertaron con el Estado en las IV Ruedas de Negocios. [Disponible en: http://www.mpc.gov.ve/portal/modules.php. Consultado el 25 de junio de 2004].

Organización Internacional del Trabajo (OIT) (1966), Recomendación № 127 de la OIT: sobre el Papel de las Cooperativas en el Progreso Económico y Social de los Países en Vías de Desarrollo. [Disponible en: http://www.neticoop.org.uy/dossier/d101.html Consultado el 17 de julio de 2004].

Organización Internacional del Trabajo (OIT) (1998), Programa "Estrategias y 
Técnicas contra la Exclusión Social y la Pobreza de la OIT'”. [Publicación en línea]. [Disponible en: http://www.ilo.org/public/spanish/protection/socsec/step/pauvrete.htm. Consultado el 17 de julio de 2004].

Organización Internacional del Trabajo (OIT) (2002), Recomendación 193 de la OIT: Recomendación sobre la Promoción de las Cooperativas. [Disponible en: http://www.ilo.org/public/ spanish/bureau/inf/magazi-

ne/48/coop.htm. Consultado el 17 de julio de 2004].

Organización Internacional del Trabajo (OIT) $(\mathrm{S} / \mathrm{F})$, Desarrollo Cooperativo. Creación de un Clima Positivo y Condiciones Favorables para el Desarrollo Cooperativo en América Latina. [Publicación en línea]. [Disponible en: http://www.ilo.org/public/ spanish/ employment/ent/papers/latiname.htm. Consultado el 17 de julio de 2004].

Organización Internacional del Trabajo (OIT) (S/F), El Trabajo Decente es Fundamental para el Progreso Social. [Disponible en: http://www.ilo.org/public/spanish/decent.htm. Consultado el 17 de julio de 2004].

Perdomo, Ninoska (2003), Con Aciertos y Desaciertos Cooperativas en Venezuela Gestionan Futuro. ADITAL [Disponible en: http://www.adital.org.br/ site/noticias/8350.asp?cod $=8350 \&$ lang $=$ ES . Consultado el 03 de julio de 2004].
Suárez, Cecilia (2003), Los Discursos que nos Atraviesan Pensamiento Radical. [Artículo en línea]. [Disponible en http://transdisciplina.tripod.com/ cecilia_suarez-34.htm Consultado el 17 de julio de 2004].

Superintendencia Nacional de Cooperativas (SUNACOOP) (2003), ¿Qué es el Cooperativismo? Consulta en línea [Disponible en: http://www.sunacoop.gov.ve/faq.htm. Consultado el 25 de junio de 2004].

Richer, Madeleine (1999), Lo Distintivo de las Organizaciones Cooperativas. Revista Venezolana de Gerencia, Año 4, № 8, Agosto 1999, Venezuela, Centro de Estudios de la Empresa, Universidad del Zulia.

Vargas. Alfonso (2001), El Cooperativismo como Fórmula Empresarial de Futuro para Canalizar el Espíritu Emprendedor Colectivo. En Galega de E, A. Revista Economía, Vol. 10, № 1, pp. 1-15. [Disponible en: http://www. usc.es/ econo/RGE/Vol\%2010_1/ Castelan/resu17e.htm. Consultado el 17de julio de 2004]. 